\title{
DETERMINAÇÃO DA COMPOSIÇÃO CENTESIMAL A PARTIR DE DOIS MÉTODOS DE SECAGEM PARA A PRODUÇÃO DA FARINHA DE BETERRABA (BETA VULGARIS, L. - FAMÍLIA AMARANTHACEAE)
}

\section{DETERMINING THE CHEMICAL COMPOSITION BASED ON TWO DRYING METHODS TO BEETROOT (BETA VULGARIS, L.- FAMÍLIA AMARANTHACEAE) FLOUR PRODUCTION}

\author{
CROCETTI, A. ${ }^{1}$; OGLEARI, C. H. '; GOMES, G. ' ; SARE, I. '; CAMPOS, F. R. ${ }^{2}$; BALBI, M. E. ${ }^{3}$
}

1 - Alunas de Graduação do Curso de Farmácia da Universidade Federal do Paraná (UFPR)

2 - Professora responsável pela disciplina de Física Industrial - Universidade Federal do Paraná - Curitiba, PR - Brasil

3 - Professora responsável pela disciplina de Bromatologia - Universidade Federal do Paraná - Curitiba, PR - Brasil

Autor para correspondência: bromatologia.ufpr@gmail.com

\section{RESUMO:}

A beterraba (Beta vulgaris, L. - Família Amaranthaceae) é uma hortaliça tuberosa que contém uma elevada quantidade de água e uma composição de vitaminas e minerais variada. Seus altos valores de carboidratos a tornam útil na produção de açúcar. Seu pigmento é um ótimo antioxidante natural que age contra o envelhecimento celular e reduz o risco de alguns tipos de câncer. A farinha pode ser introduzida na dieta em receitas que podem ser adaptadas para seu uso, como por exemplo, em bolos e pães, além de sua pigmentação específica (devido à betalaína e ferro) ser atraente aos consumidores. Foram utilizadas duas técnicas diferentes para a obtenção da farinha: por secagem em estufa e por liofilização e, em seguida, foram realizados testes macroscópicos e determinação da composição química e nutricional das farinhas obtidas. Observou-se que as farinhas apresentavam maior concentração de nutrientes quando comparados à beterraba crua. $\mathrm{A}$ farinha obtida por liofilização apresentou valores mais altos de proteínas, carboidratos e fibras, o que pode ser explicado por a liofilização não expor os compostos a altas temperaturas, reduzindo as reações de decomposição desses nutrientes. Além disso, observou-se que a coloração da farinha liofilizada se manteve mais semelhante à beterraba crua quando comparada com a farinha obtida por secagem em estufa, devido às possíveis reações de caramelização e/ou Maillard que podem ocorreram. Conclui-se então que o processo de liofilização gera um produto com menor perda de características (como cor e propriedades organolépticas), porém é preciso estudar o uso de conservantes durante o processo para reduzir a higroscopicidade do produto obtido.

PALAVRAS-CHAVE: Beterraba. Farinha de beterraba. Secagem em estufa. Liofilização. Composição centesimal. Beta vulgaris, L.

\section{ABSTRACT:}

The beetroot (Beta vulgaris, $L$. - Family Amaranthaceae) is a tuberous vegetable that has a high quantity of water and a varied composition of vitamins and minerals. Its high levels of carbohydrates makes it useful in sugar production. Its pigment is a great natural antioxidant 
that acts against aging and lower the risks of some types of cancer. The flour can be introduced in the feeding through adapted recipes, like cakes and bread. Besides, its specific pigmentation (due to betalain and iron) may appeal to whom will consume these products. Two methods were used to obtain the flour, by heat drying and lyophilization, and then went through macroscopic tests and determination of chemical and nutritional composition of the obtained flours. It was observed that the flours had a reduction in humidity and a concentration of its nutrients when compared to the raw beetroot. The flour obtained through lyophilization presented the highest levels of nutrients such as proteins, carbohydrates and fibers, which can be explained because the lyophilization doesn't expose the nutrients to high temperatures, reducing their degradation. Besides, we could see that the color of the lyophilized flour was similar to the raw beetroot when compared to the heat dryied flour due to possible caramelization reactions and/or Maillard reaction that may occur. We can conclude that the lyophilization process obtains a flour with less loss of qualities (like color and organoleptic properties). However, there's a need to study the use of preservatives to reduce the hygroscopicity of the final product

KEYWORDS: Beetroot. Beetroot flour. Heat drying. Lyophilization. Chemical composition. Beta vulgaris, L.

\section{INTRODUÇÃO}

A Beta vulgaris L., é uma planta herbácea da família das Amaranthaceae. (THE INTERNATIONAL PLANT NAMES INDEX, 2004). Existem diversas variações da espécie, como por exemplo a beterraba açucareira (usada para produção de açúcar), a beterraba forrageira (usada para alimentação animal) e aquela cujas raízes são consumidas como hortaliça, sendo a mais conhecida no Brasil. Existem diferentes espécies, sendo apenas cultivadas em determinadas partes do mundo, devido às condições ambientais dessas áreas (Canadian Food Inspection Agency, 2012).

A produtividade média da beterraba é de 30 a 40 toneladas por hectare, sendo, no Brasil, os maiores produtores os Estados de: São Paulo, Minas Gerais, Paraná, Santa Catarina e Rio Grande do Sul, onde se encontram $42 \%$ das propriedades produtoras (GRANGEIRO et al., 2007). A produção em regiões mais quentes é reduzida, pois a temperatura mais elevada tende a alterar o desenvolvimento da beterraba (como por exemplo, a redução da pigmentação) e consequentemente, altera a qualidade do produto (APHORTESP, 2009).

A beterraba é uma hortaliça tuberosa, que possui uma elevada quantidade de água e uma composição variada de vitaminas e minerais, com altos valores para carboidratos. Devido à isso seu uso na produção de açúcar está sendo cada vez mais utilizado mundialmente. Possui uma elevada quantidade de fibras e carboidratos, e uma quantidade mínima de gorduras, podendo essa ser desconsiderada. Os minerais: potássio, sódio, fósforo, magnésio e cálcio apresentam valores significativos por porção, sendo todos esses 
envolvidos em metabolismos enzimáticos importantes para o organismo (USDA, 2014).

São ricas em ácido fólico (USDA, 2014), sendo então uma opção para grávidas, que têm maior necessidade deste para uma boa formação do feto. O ácido ascórbico, importante antioxidante, também está presente em quantidade na beterraba, e apesar desta possuir baixas concentrações de ferro, a associação com a vitamina garante a sua absorção eficaz, por esse motivo, é recomendada no tratamento de anemias e também auxilia no tratamento de distúrbios do fígado e do baço.

A Beta vulgaris, L. (Família Amaranthaceae) possui coloração avermelhada devido à presença de betalaína. Esta substância é um ótimo antioxidante natural, que age contra o envelhecimento celular e reduz o risco de alguns tipos de câncer (KLUGE et al., 2006). Além disso, a betalaína pertence ao grupo de nitrogenados alcaloides, podendo então ser substrato para a produção de óxido nítrico, causando vasodilatação, melhorando o fluxo sanguíneo e a passagem de oxigênio. Por isso algumas pesquisas têm demonstrado que esse efeito reduz os riscos de doenças como o acidente vascular cerebral e demência recentemente ela tem sido apontada como importante fator para redução da hipertensão (CORREIA et al., 2009).

A elaboração da farinha foi idealizada no intuito de encontrar alternativas para a introdução do tubérculo na dieta tanto infantil (por não apresentar o tubérculo próprio, facilita a aceitação da criança), quanto na dieta de adultos e adolescentes (uso mais rápido e prático da farinha, comparando com o uso da beterraba cozida, ingerida na salada).

A introdução da farinha da Beta vulgaris, L. (Família Amaranthaceae), pode ser feita de vários modos, como por exemplo, aplicação em receitas que podem ser adaptadas para seu uso (em bolos e pães) sendo usado como aditivo nutricional. Além das relevantes importâncias nutricionais, a pigmentação avermelhada da beterraba pode ser atraente aos consumidores dos produtos feitos com a farinha. Tem-ser feito estudos baseados na fortificação das farinhas com ferro na tentativa de promover aumento nas médias de hemoglobina em crianças, após um determinado tempo de consumo. Esses acréscimos nem sempre são eficientes devido ao consumo de quantidades insuficientes dessas farinhas por crianças, pela baixa biodisponibilidade do ferro adicionado ao produto ou ainda pela ingestão de alimentos que inibem a absorção de ferro (ASSUNÇÃO et al., 2007). A forma de farinha constitui boa opção tecnológica de aproveitamento da matéria-prima e como fonte nutricional para possíveis formulações de produtos alimentícios (CAPELLA et al., 2009).

No estudo feito, analisou a composição química e nutricional da beterraba crua e 
das suas respectivas farinhas, utilizando dois métodos de secagem diferentes: em estufa e liofilização. Comparou os resultados obtidos, para verificar se os processos de secagem mantém os compostos nutricionais, observando se o uso da farinha traria benefícios nutricionais como a beterraba crua.

\section{MATERIAL E MÉTODOS}

\subsection{Preparo do material}

As beterrabas (Beta vulgaris, L. - Família Amaranthaceae) foram adquiridas na feira ao ar livre do bairro Cristo Rei (Curitiba - PR), procedentes do município de Colombo (região metropolitana de Curitiba)., em março de 2015.

Foram armazenadas em sacos plásticos e sob refrigeração até serem transportadas para o Laboratório de Bromatologia da UFPR. Lá, foram higienizadas, descascadas e picadas em pequenos cubos (manualmente, utilizando facas; os cubos tinham tamanho semelhante, tentando manter um padrão).

Parte destes cubos foram secos em estufa $\left(\right.$ a $50^{\circ} \mathrm{C}$ ), e depois foram trituradas em processador de lâminas. Outra parte foi seca usando o método de liofilização (em Liofilizador do modelo BENCHTOP 8L XL-70), sendo essas previamente preparadas, fazendo o pré-congelamento em congelador a $-40^{\circ} \mathrm{C}$, seguido por congelamento por imersão em nitrogênio líquido. O produto liofilizado foi triturado usando pistilo e graal.

\subsection{Metodologia}

Foram realizadas análises macroscópicas, químicas e físico-químicas, e também, foi feita a determinação da porção para as amostras de beterraba, farinha seca em estufa e farinha obtida por liofilização.

- Análises macroscópicas, observando características como coloração, granulação, higroscopicidade, odor e afins;

- $\quad$ Determinação de umidade, usando método de secagem em estufa (IAL, 2008);

- Determinação de nitrogênio total pelo método de Kjeldahl (AOAC $\left.{ }^{b}, 1995\right)$, usando o fator de conversão de proteínas 5,75 segundo a RDC n 360 (BRASIL ${ }^{a}, 2003$ )

- Determinação de extrato etéreo, usando método de extração soxhlet (IAL, 2008);

- $\quad$ Determinação de cinzas ou matéria mineral, por incineração em mufla (IAL, 2008);

- $\quad$ Determinação de fibras (AOAC $\left.{ }^{a}, 1970\right)$;

- Determinação de carboidratos por diferença, obtendo a fração Nifext segundo RDC no 360 (BRASIL $\left.{ }^{a}, 2003\right)$. 
- Determinação de porção foi feita seguindo o método de cálculo da ANVISA (BRASIL, 2005). Utilizou-se 1/2 xícara (50 g) como medida caseira segundo a RDC nํ 359 (BRASIL ${ }^{b}, 2003$ ), baseando-se no peso da farinha de trigo para os cálculos.

- Os cálculos das informações nutricionais e dos valores diários recomendados (VDR\%) foram feitos segundo a RDC n³60 (BRASIL ${ }^{a}, 2003$ ).

Os tratamentos estatísticos dos dados coletados foram feitos a partir das médias dos resultados e cálculo de desvio padrão. Ainda serão feitas análises de Tukey e teste de ANOVA, para finalizarmos os estudos e avaliar se as diferenças entre os resultados foram realmente significativas.

\section{RESULTADOS E DISCUSSÕES}

3.1 Comparação dos resultados das análises de composição da beterraba (Beta vulgaris, L. - Família Amaranthaceae) crua e suas farinhas (seca em estufa e liofilizada)

Os valores da composição química e nutricional da matéria prima, Beterraba (Beta vulgaris, L. - Família Amaranthaceae), da farinha seca em estufa a $50^{\circ} \mathrm{C}$ e da farinha liofilizada, podem ser observados na tabela 1.

TABELA 1. RESULTADOS DA COMPOSIÇÃO CENTESIMAL DA BETERRABA CRUA, FARINHA SECA EM ESTUFA E FARINHA LIOFILIZADA

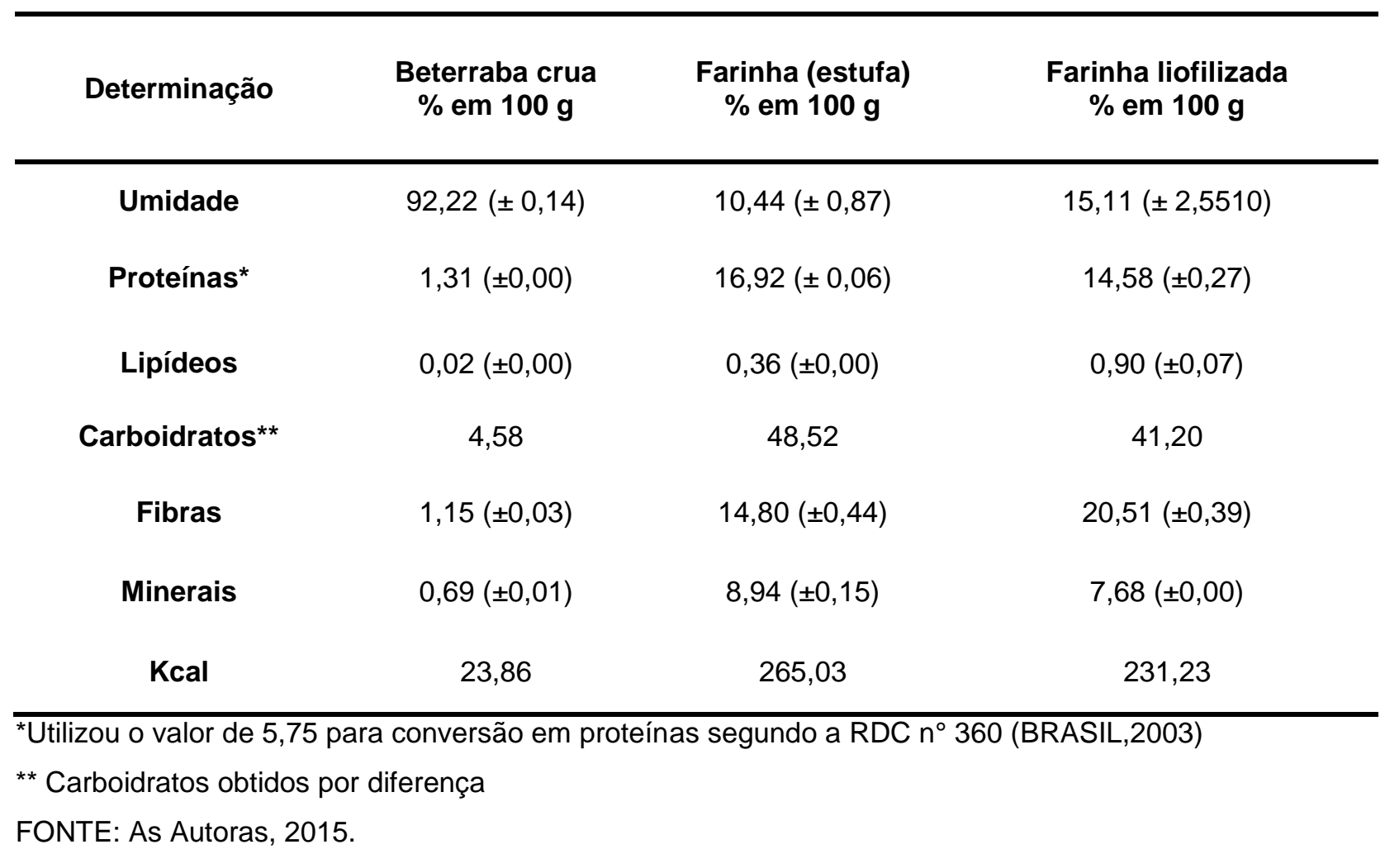


Os valores obtidos para a farinha de beterraba seca em estufa podem ter sido alterados pelo tempo de secagem acima do recomendado, que seria a $100^{\circ} \mathrm{C}$ por $2 \mathrm{~h}$ seguido de $70^{\circ} \mathrm{C}$ (ARAUJO FILHO, 2011). Foi utilizada a secagem a $50^{\circ} \mathrm{C}$ pois utilizamos a beterraba obtida do preparo da matéria seca para preparar a farinha seca em estufa. Seria interessante realizar pesquisas para verificar a qualidade da farinha obtida pelo método de secagem em estufa, aplicando temperaturas diferentes e utilizando estufas diferentes (com e sem ar circulante, usando grades ou bandejas como suporte).

A análise macroscópica, observou que a beterraba crua possuía características normais da hortaliça saudável: apresentavam forma globosa, coloração purpúrea (interna e externamente), devido aos pigmentos betalaína e betaxantina (TIVELLI et al., 1990). Não apresentavam sinais de decomposição e manchas aparentes.

$\mathrm{Na}$ farinha seca em estufa, observamos que houve escurecimento do produto (perda da coloração da beterraba crua). Como a beterraba (Beta vulgaris, L. - Família Amaranthacea) apresenta valores significativos de açúcares (KÜHNEL et. al, 2011) e proteínas, e para a produção da farinha em estufa, houve exposição desses componentes a altas temperaturas, supões que esse escurecimento ocorreu devido processos de caramelização e/ou Reação de Maillard. A farinha obtida pelo processo de liofilização não expos seus componentes a temperaturas altas, por isso manteve sua coloração, odor e sabor similares a beterraba crua. Isso pode ser observado na figura 01 .

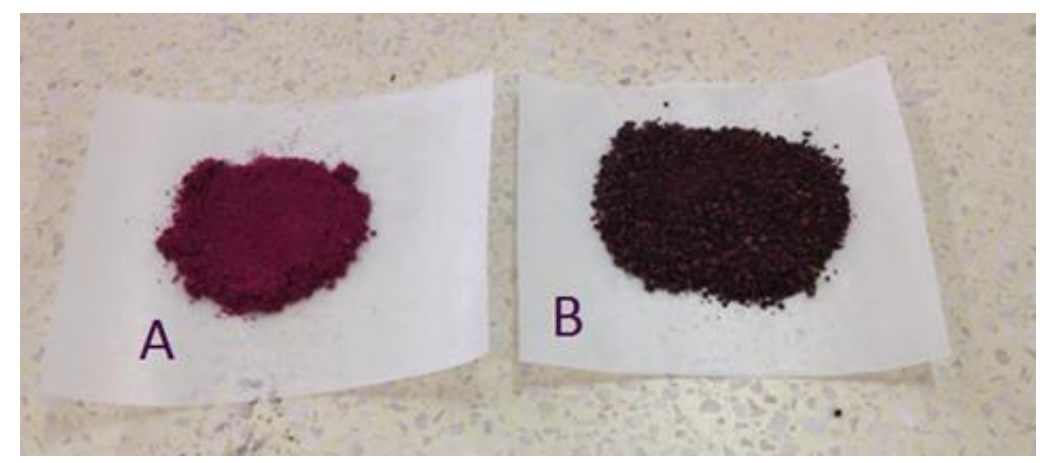

Figura 01 - Comparação macroscópica das farinhas de beterraba (Beta vulgaris, L- Família Amaranthacea). Farinha liofilizada - A; Farinha seca em estufa - B. FONTE: As Autoras, 2015.

As propriedades organolépticas das duas farinhas foram diferentes:

- O odor da farinha seca em estufa foi mais doce, mas a farinha liofilizada mantinha o odor semelhante ao da beterraba (Beta vulgaris, L. - Família Amaranthacea) ainda crua; 
- O sabor da farinha liofilizada praticamente se manteve o mesmo, ao contrário da seca em estufa que teve um sabor sutil da hortalilça crua;

- A textura das duas foi completamente diferente: a liofilizada se hidratava na boca, ficando mais agradável ao paladar, e a seca em estufa era mais doce, com granulos irregulares, rígidos e menos agradável ao paladar.

Notou também, a alta higroscopicidade de ambas as farinhas, mas principalmente da farinha liofilizada. No processo da trituração dos cubos liofilizados, já se visualizava a hidratação ocorrendo, tendo a formação de grumes com a absorção da umidade do ambiente, que ocorria em segundos.

A umidade da beterraba crua foi razoavelmente alta, sendo esse o motivo do baixo rendimento de produção das farinhas (foram usados aproximadamente 6 quilogramas e para obter poucos gramas de farinha, em ambos os métodos).

O valor encontrado para umidade na farinha liofilizada foi maior, por ser altamente higroscópico, como já esperado, e por ser um produto liofilizado. Isso também justifica o alto desvio padrão para esses valores. Porém, seria interessante repetir esse experimento, já que as alterações nos valores da umidade podem causar erros nos cálculos de carboidratos (obtidos por diferença - NIFEXT).

Os valores nutricionais obtidos para as farinhas, quando comparadas com a beterraba crua, foram muito maiores. Essa diferença ocorreu pois a secagem fez com que os compostos ficassem mais concentrados. Isso é um fator favorável, já que a aplicação das farinhas como suplemento (na produção de bolos e afins), irá adicionar valores nutricionais nesses alimentos, como o que se buscava (conforme os objetivos).

A farinha liofilizada teve menor teor de proteínas do que a seca em estufa, podendo ser explicado devido a maior quantidade de outros nutrientes (como por exemplo as fibras e lipídios), reduzindo assim, proporcionalmente, a quantidade de proteína encontrada na farinha liofilizada.

Quanto aos valores de gorduras, a farinha seca em estufa teve menores valores de lipídios do que a seca por liofilização. A exposição a altas temperaturas gera a degradação desses óleos, justificando a redução da suas concentrações na farinha seca em estufa. Além disso, os óleos de baixo peso molecular, responsáveis pelo sabor e aroma, não foram perdidos com a liofilização já que não foram degradados, mantendo as características organolépticas semelhantes com a beterraba (Beta vulgaris, L. - Família Amaranthacea) ainda crua.

A diferença da quantidade de minerais encontrada entre as duas farinhas não foi 
muito grande, podendo se afirmar se essa diferença foi significativa apenas após as análises estatísticas. Mas ainda serão analisados os teores de magnésio e ferro nas farinhas, que na beterraba crua, são os minerais de maior concentração e interesse (agregação de valores nutricionais pela presença desses componentes). Também, a quantidade de vitaminas como ácido ascórbico e ácido fólico, para verificar se houveram alterações significativas nesses valores com a secagem.

A farinha liofilizada teve maior concentração de fibras quando comparada com a seca em estufa. Isso ocorre pelas alterações nas fibras causadas pela exposição ao calor.

$\mathrm{Na}$ farinha seca em estufa, houve caramelização e reação de Maillard, devido a exposição desses carboidratos a altas temperaturas, que é o principal fator responsável pela alteração no sabor quando comparada com a liofilizada.

A farinha liofilizada teve menor quantidade de carboidrato do que a seca em estufa. Esse valor reduzido se dá ao fato de compensar os maiores valores encontrados dos outros nutrientes (assim como o valor de proteínas, citado anteriormente).

Quanto aos valores energéticos, devido à maior concentração dos componentes nutricionais nas farinhas, estas são mais calóricas em relação a beterraba crua. Porém, as calorias são decorrentes de nutrientes necessários em uma dieta saudável, sendo então justificada, mais uma vez, a introdução das farinhas na alimentação da população.

A farinha liofilizada possui menor valor energético que a seca em estufa devido aos menores valores de carboidratos e proteínas, e pelo seu maior teor de fibras, que devido a não ser exposto a altas temperaturas, mantiveram a estrutura, "ocupando" o lugar dos outros nutrientes na porção analisada.

Observamos que os valores nutricionais para as farinhas são semelhantes, mas o método de liofilização, apesar de ter um processo pouco mais trabalhoso que a secagem em estufa e ter um armazenamento que necessita de mais cuidados (por ser altamente higroscópico), foi o processo que obteve os melhores resultados.

Os valores da composição da beterraba (Beta vulgaris, L. - Família Amaranthacea) e das suas farinhas (liofilizada e seca em estufa) foram convertidos de porcentagem (100 g dos produtos) para porções, conforme RDC 360 (BRASIL $\left.{ }^{a}, 2003\right)$. As porções utilizadas neste trabalho foram $50 \mathrm{~g}, 1 / 2$ xícara, utilizando a medida usada para a farinha de trigo para facilitar a comparação. Foi determinado também seu VDR\% (Valor Diário de Referência), como podemos observar na Tabela 2: 
TABELA 2. Informação nutricional das porções e valor diário de referência (VDR\%) da beterraba crua (Beta vulgaris, L. - Família Amaranthacea) e das suas farinhas (seca em estufa e liofilizada

\begin{tabular}{c|c|c|c|c|c|c}
\hline & \multicolumn{2}{|c|}{ Beterraba (crua) } & \multicolumn{2}{c|}{ Farinha seca em estufa } & \multicolumn{2}{c}{ Farinha liofilizada } \\
\hline Informações & $\begin{array}{c}\mathbf{g} / \mathbf{1} \text { un } \\
(\mathbf{1 4 0} \mathbf{g})\end{array}$ & VDR (\%)* & $\begin{array}{c}\mathbf{g} / \mathbf{5 0} \mathbf{g} \text { de } \\
\text { porção }\end{array}$ & VDR (\%) & $\begin{array}{c}\text { g/ 50 g de } \\
\text { porção }\end{array}$ & VDR (\%) \\
\hline Carboidratos & 6,421 & 2 & 24,26 & 8 & 20,60 & 7 \\
\hline Proteínas & 1,84 & 2 & 8,46 & 11 & 7,29 & 10 \\
\hline $\begin{array}{c}\text { Gorduras } \\
\text { totais }\end{array}$ & 0,03 & $*$ & 0,18 & $*$ & 0,45 & $*$ \\
\hline Fibras & 1,61 & 6 & 7,40 & 30 & 10,25 & 41 \\
\hline Kcal & 33,40 & 2 & 132,51 & 66 & 115,61 & 58 \\
\hline
\end{tabular}

*Valores não significativos

** Segundo a RDC n³60 (BRASILa, 2003)

3.2 Comparação das farinhas (liofilizada e seca em estufa) da beterraba (Beta vulgaris, L. - Família Amaranthacea) com outras farinhas

Comparando os valores obtidos para a farinha de beterraba (Beta vulgaris, L. Família Amaranthacea) com a farinha de trigo, conforme a tabela 3, observamos maiores valores nas proteínas, fibras e lipídios para a farinha de beterraba.

TABELA 3. INFORMAÇÃO NUTRICIONAL DA FARINHA DE TRIGO

\begin{tabular}{ccc}
\hline Informações & $\mathbf{1 / 2}$ Xícara $(\mathbf{5 0} \mathbf{~ g})$ & VDR $(\%)^{* *}$ \\
\hline Carboidratos & 38 & 13 \\
Proteínas & 5 & 7 \\
Gorduras totais & 0 & $*$ \\
Fibras & 1,2 & 5 \\
Kcal & 180 Kcal & 7 \\
$*$ Valor não significativo & \\
** Segundo a RDC $\mathrm{n}^{\circ}$ 360 (BRASILa, 2003) & & \\
FONTE: ANVISA (BRASIL, -) & \\
\hline \hline
\end{tabular}


A composição rica em nutrientes da farinha de beterraba é mais um benefício do seu uso como aditivo em alimentos. Seriam necessárias pesquisas reológicas da farinha, para avaliar se seria possível ou não o seu uso isolado em receitas de massas.

Outra comparação feita, foi com a farinha de pinhão (CAPELLA et al., 2009). Essa análise foi feita pois, assim como a farinha de beterraba, é uma farinha não muito utilizada, mas que poderia ser mais popularizada com o reconhecimento de seus benefícios nutricionais. Observando a tabela 4, nota-se que as farinhas de pinhão possuem menos umidade, proteínas e fibras se comparados ao pinhão fresco, tanto cru, quanto cozido. Nas farinhas de beterraba, não se observa essa perda com a secagem, pois observa que o produto desidratado (farinhas) possui valores de proteínas e fibras maiores que do produto cru.

Isso pode ter ocorrido pois degradação que ocorreu na produção da farinha de pinhão não ocorreu em mesma potência que na produção das farinhas de beterraba. Esse fato pode estar relacionado a maior quantidade de água encontrada na beterraba crua quando comparada com a umidade do pinhão cru. Também, devemos levar em consideração as diferentes características dos produtos, considerando que a beterraba possui esses valores já elevados em relação a outros alimentos.

TABELA 4 - COMPOSIÇÃO CENTESIMAL (g/100 g) DAS SEMENTES DE Araucaria angustifolia E FARINHAS DE PINHÕES SUBMETIDAS À SECAGEM A 65드 (CAPELLA et al., 2009).

\begin{tabular}{|c|c|c|c|c|c|c|}
\hline \multirow{2}{*}{$\begin{array}{l}\text { Tratamento } \\
\text { (2) }\end{array}$} & \multicolumn{6}{|c|}{ COMPOSIÇÃO CENTESIMAL (g/100 g) EM BASE SECA(1) } \\
\hline & UMIDADE & PROTEÍNAS* & LIPÍDEOS* & CINZAS* & FIBRA* & CARBOIDRATO* \\
\hline CRF & $\begin{array}{c}51,16( \pm 0,29) \\
A\end{array}$ & $\begin{array}{c}6,59( \pm 0,15) \\
A\end{array}$ & $\begin{array}{c}7,38( \pm 0,31) \\
A B\end{array}$ & $\begin{array}{c}2,85( \pm 0,36) \\
A\end{array}$ & $\begin{array}{c}15,34( \pm 0,25) \\
B\end{array}$ & $67,84 \mathrm{C}$ \\
\hline COZF & $\begin{array}{c}49,70( \pm 0,25) \\
B\end{array}$ & $\begin{array}{c}6,31( \pm 0,15) \\
A\end{array}$ & $6,27( \pm 0,31) \mathrm{B}$ & $\begin{array}{c}3,57( \pm 0,68) \\
A\end{array}$ & $\begin{array}{c}16,88( \pm 0,23) \\
A\end{array}$ & $66,96 \mathrm{C}$ \\
\hline CRF65 & $\begin{array}{c}8,29( \pm 0,34) \\
C\end{array}$ & $\begin{array}{c}3,07( \pm 0,06) \\
C\end{array}$ & $6,39( \pm 0,35) \mathrm{B}$ & $\begin{array}{c}2,53( \pm 0,14) \\
A\end{array}$ & $\begin{array}{c}6,45( \pm 0,54) \\
C\end{array}$ & $81,56 \mathrm{~A}$ \\
\hline COZF65 & $\begin{array}{c}13,85( \pm 0,34) \\
C\end{array}$ & $\begin{array}{c}3,41( \pm 0,02) \\
B\end{array}$ & $5,14( \pm 0,56) C$ & $\begin{array}{c}3,01( \pm 0,80) \\
A\end{array}$ & $\begin{array}{c}5,11( \pm 0,11) \\
C\end{array}$ & $83,38 \mathrm{~A}$ \\
\hline
\end{tabular}

NOTA: (1) Os dados apresentados correspondem aos valores médios das análises das amostras feitas em triplicata. Médias seguidas por letras distintas nas colunas diferem entre si pelo teste de Tukey, com significância de $5 \%(p \leq 0,05)$.

(2) $\mathrm{CRF}=$ pinhão fresco e cru; $\mathrm{COZF}$ = pinhão fresco cozido; $\mathrm{CRF} 65$ = farinha de pinhão cru desidratada a $65^{\circ} \mathrm{C}$; COZF65 = farinha de pinhão cozido desidratada a $65^{\circ} \mathrm{C}$.

$\left.{ }^{*}\right)$ Valores em base seca. 


\section{CONCLUSÃO}

Obtivemos sucesso com a produção das farinhas, utilizando ambos os processos. Porém, podemos ainda estudar melhor o processo de obtenção em estufa, avaliando as temperaturas e os tipos diferentes de estufa que poderiam ser usados para otimizar o processo.

Observamos os processos de caramelização e/ou Maillard na farinha seca em estufa, além da perda das características organolépticas da sua matéria prima, a beterraba crua (Beta vulgaris, L. - Família Amaranthacea).

A farinha obtida pelo processo da liofilização, manteve a coloração, sabor e odor muito semelhantes a da beterraba crua. Isso devido a não exposição a temperaturas brandas, como na produção da farinha seca em estufa.

Dependendo do objetivo da aplicação da farinha, uma sobrepõe suas vantagens sobre a outra. Por exemplo, caso queira se ter a produção de bolos e tortas que não tenham a coloração e o sabor da beterraba, para crianças por exemplo, utilizaríamos a farinha seca em estufa. Mas se o objetivo fosse ter um produto com as características que lembrem a beterraba crua, a farinha liofilizada seria a melhor opção.

Porém, devemos ainda avaliar se houve a perda de compostos termosensíveis (vitaminas) nas farinhas, para avaliar qual seria 0 consumo mais vantajoso nutricionalmente.

Seria interessante também, ter uma continuidade da pesquisa quanto à adição de conservantes para reduzir a higroscopicidade da farinha e quanto à aplicação do produto na dieta da família brasileira (popularizar o produto, passando o conhecimento sobre os seus benefícios) e observando a aceitação da farinha.

\section{REFERÊNCIAS}

ANVISA ${ }^{a}$ - AGENCIA NACIONAL DE VIGILÂNCIA SANITÁRIA. Modelos de rótulos de alimentos: Produtos de Panificação, Cereais e Outros Grãos, Raízes e Tubérculos. Disponível em: http://portal.anvisa.gov.br/wps/content/Anvisa+Portal/Anvisa/Inicio/Alimentos/ Publicacao+Alimentos/Farinha+de+Trigo > Acesso em 20/05/2015.

ANVISA ${ }^{b}$ - AGENCIA NACIONAL DE VIGILÂNCIA SANITÁRIA. Rotulagem Nutricional Obrigatória: Manual de Orientação às Indústrias de Alimentos. $2^{\circ}$ Versão. Universidade 
de Brasília, 2005. 44p. Disponível em: <http://portal.anvisa.gov.br/wps/wcm/connect/5f53be 80474583c58ee8de3fbc4c6735/manual_industria.pdf?MOD=AJPERES> Acesso em 20/05/2015.

AOAC ${ }^{a}$. ASSOCIATION OF OFFICIAL AGRICULTURAL CHEMISTS. Official Methods of Analysis. 12th ed. USA: ASSOCIATION OF OFFICIAL AGRICULTURAL CHEMISTS, Washington D.D. 1970.

AOAC ${ }^{b}$. ASSOCIATION OF OFFICIAL AGRICULTURAL CHEMISTS. Official Methods of Analysis. 12th ed. USA: ASSOCIATION OF OFFICIAL AGRICULTURAL CHEMISTS, Washington D.D. 1995.

APHORTESP - Associação dos Produtores de Horti-Fruti do Estado de São Paulo. Beterraba. Disponível em: <http://www.aphortesp.com.br/beterraba.html>. Acesso em 10/04/2015.

ARAUJO FILHO, D. G. Processamento de produto farináceo a partir de beterrabas. Acta Scientiarum. Agronomy. Maringá, v. 33, n. 2, p. 207-214, 2011. Disponível em: <http://www.scielo.br/pdf/asagr/v33n2/03.pdf> Acesso em 20/05/2015.

ASSUNCAO, Maria Cecília Formoso et al . Efeito da fortificação de farinhas com ferro sobre anemia em pré-escolares, Pelotas, RS. Rev. Saúde Pública, São Paulo, v. 41, n. 4, p. 539548, Ago. 2007. Disponível em: <http://www.scielo.br/scielo.php?script=sci_arttext\&pid= S0034-89102007000400007\&lng=en\&nrm=iso >. Acesso em 19/06/2015.

BRASIL ${ }^{\text {a }}$ ANVISA. Agência Nacional de Vigilância Sanitária. Resolução RDC no. 360, de 23 de dezembro de 2003. ANVISA. Regulamento Técnico sobre Rotulagem Nutricional de Alimentos Embalados. Diário Oficial da União, Brasília, DF, 26 dez. 2003.

BRASIL ${ }^{\text {}}$. ANVISA. Agência Nacional de Vigilância Sanitária. Resolução RDC no 359, de 23 de dezembro de 2003. ANVISA. Regulamento Técnico de Porções de Alimentos Embalados para Fins de Rotulagem Nutricional. Diário Oficial da União, Brasília, DF, 26 dez. 2003.

Canadian Food Inspection Agency. The Biology of Beta vulgaris L. (Sugar Beet). Disponível em: <http://www.inspection.gc.ca/plants/plants-with-novel-traits/applicants/directive- 
94-08/biology-documents/beta-vulgaris-l-/eng/1330725373948/133072543734>. Acesso em 10/04/2015.

CAPELLA, A.C.V.; PENTEADO, P.T.P.S.; BALBI, M.E. Semente de Araucaria Angustifolia: aspectos morfológicos e composição química da farinha. B.CEPPA, Curitiba v. 27, n. 1, p. 135-142 jan./jun. 2009. Disponível em: <http://ojs.c3sl.ufpr.br/ojs/index.php/alimentos/article/ view/15009/10059>. Acesso em 19/06/2015.

CORREIA, A. S. et al. As Propriedades Físico-químicas da Beterraba, 2009. Artigo de Graduação (Licenciatura em Química) - Instituto Federal de Educação, Ciência e Tecnologia de Sergipe.

Economia IG. Produção de açúcar de beterraba supera a de cana. Acesso em 10/04/2015 ás 20:37. Disponível em: <http://economia.ig.com.br/empresas/agronegocio/ producao-de-acucar-de-beterraba-supera-a-de-cana/n1597189615198.html>. Acesso em 10/04/2015.

GRANGEIRO L. C. et al. Acúmulo e exportação de nutrientes em beterraba. Ciênc. agrotec. vol.31 no.2 Lavras Mar./Apr. 2007 . Disponível em: <http://www.scielo.br/scielo. php?script=sci_arttext\&pid=S1413-70542007000200001\&lng=en\&nrm=iso>. Acesso em 10/04/2015.

IAL. Instituto Adolfo Lutz. Normas analíticas do Instituto Adolfo Lutz: métodos químicos e físicos para análise de alimentos. São Paulo: Instituto Adolfo Lutz. 2008. 1020p.

KLUGE, R. A. et al. Armazenamento refrigerado de beterraba minimamente processada em diferentes tipos de corte. Ciência Rural, Santa Maria, v.36, n.1, p.263-270, jan-fev, 2006. Disponível em: <http://www.scielo.br/pdf/cr/v36n1/a41v36n6.pdf>. Acesso em 10/04/2015.

KÜHNEL, S. et. al. Bioethanol from Sugar Beet Pulp - The Pectin Challenge. Wageningen University - Department of Agrotechnology and Food Sciences, 2011. Disponível em: <http://www.dyadic.nl/Publications/Bioethanol\%20from\%20Sugar\%20Beet \%20Pulp_The\%20Pectin\%20Challenge.pdf > Acesso em: 19/06/2015. 
THE INTERNATIONAL PLANT NAMES INDEX. Beta vulgaris L. Disponível em: $<$ http://www.ipni.org/ipni/plantNameByVersion.do?id=165468-3\&version=1.2\&output_Format= Isid-metadata\&show_history=true> .Acesso em 08/04/2015 ás 8:03

TIVELLI, S. W et. al. Beterraba: do plantio à comercialização. Campinas: Instituto Agronômico (Série Tecnologia APTA. Boletim Técnico IAC, no 210), 2011. 45p. Disponível em: <http://www.iac.sp.gov.br/publicacoes/publicacoes_online/pdf/bt_210.pdf>.Acesso em 19/06/2015.

USDA - United States Department of Agriculture Agricultural Research Service. National Nutrient Database for Standard Reference. Release 27, 2014. Disponível em: <http://ndb.nal.usda.gov/ndb/foods>. Acesso em 10/04/2015. 